her critical dissection of some typical staff/parent interactions.

I also found Ms Anspach's observations on "producing assent" cause for a bit of introspective analysis. As she states (page 166): "Members of the nursery staff do not usually follow a policy of informed consent, but rather employ a set of practices to elicit parents' assent to decisions that have already been made". Her insights into the ways in which the staff appeared to coerce parental consent to decisions already made, with complete disregard for the parents' needs and desires was a recurrent theme in many of the conversations which she quotes. The perceived need to conceal from parents any signs of differences of opinion among the staff is symptomatic of a haughtiness which is unacceptable in the current medical climate. The arrogance with which the medical staff so often discounted parents' feelings about their baby was at times frightening.

On the other hand, medical inaccuracies such as referring to phototherapy lights as ultraviolet lights, do tend to make medical professionals look askance at any further conclusions. In a situation such as this, there exists a definite danger of overgeneralising from quite limited observations in the face of inadequate understanding. The author's observations are based on sixteen months' observation spent in two different nurseries. Both the breadth and depth of the data intake are potentially problematic. As clearly noted, the practice of medical ethics is influenced by cultural and socioeconomic factors which would be expected to vary with populations and locale. Observation in two nurseries hardly seems sufficient to characterise the behaviour of thousands of physicians and nurses across the world.

Secondly, the period of time is also limited: in sixteen months, even in the busiest of nurseries, how many lifeand-death decisions can there be? Finally, I question the accuracy of some of the assumptions proposed. Throughout the book, physicians seem to come across as arrogant, cold, distant, and uncaring - the more senior the physician, the more out of touch. Is it possible that these senior staff members merely spent less time discussing and explaining their thought processes with the author? For example, on page 185 we are introduced to an attending physician who states: "And for your notes, this is a very difficult ethical problem, the problem of iatrogenesis. I'm not particularly anxious to be called into court and it is not in my self interest to have this baby survive". This is a highly incendiary remark which can cause a tremendous amount of harm and distrust if picked up by a parent support group. I am troubled by what I feel to be an underlying tendency in Deciding Who Lives to oversimplify and as a result, to trivialise - a most complex issue.

Finally, I am left with a sense that this book is dated. I find it hard to imagine that some of the conversations cited took place in the current atmosphere, which has becoming increasingly sensitive over the last ten years. In addition, although the legal need for ethics committee approval is mentioned, the committees themselves are most conspicuous by their absence in any clinical decision making role in the representative cases cited. Furthermore, for a book released in 1997, I find it glaring that there is not one reference in the bibliography dated after 1990 . The author states that this book is not a study of the philosophy, but rather of the practicality of decision making. There is a danger that as the realities of practical decision making change, observations such as those presented here will quickly become anachronistic.

In conclusion, this is an extremely important area of investigation and Deciding Who Lives offers some meaningful and eye-opening insights into the ways in which we function - both positive and negative. There is much we can all learn from Renee Anspach's analytical examination of the patterns of our decision making and interactions with patients, with parents and with colleagues.

CATHY HAMMERMAN, MD

Department of Neonatology Shaare Zedek Medical Center, Ferusalem Israel

\section{Who Cares? The Great British Health Debate}

\section{Oliver Morgan, Oxford, Radcliffe Medical Press, 1998, 240 pages, $£ 18.50$.}

In 1948 could the health professionals and the public alike, have conceived of the changes which would shape the National Health Service (NHS) in the following fifty years? While we celebrate and reminisce at the time of the NHS's fiftieth birthday, Oliver Mor- gan takes the reader first into the fantasy world of 2048, stretching thes imagination to consider new scenarios $\Rightarrow$ of health care provision. Following the back-to-the-future trip, Morgan takeso the reader back in time, for a bird's eye view of the first fifty years of the NHS.心

The strength of the book is in its $\vec{D}$ well-researched, informative coverage of a number of themes (with frequentes reference to the views of leading health $\overrightarrow{0}$ policy formers, analysts and healthprofessionals): the accountability and $\vec{\omega}$ clinical freedom of medical professionals; the consistent difficulties in achieving an equitable provision of health services, and the government's role in shaping health services. These themes are explored with particular ${ }^{+}$ reference to the internal market; the $\infty$ role of doctors; accountability to the음 public; the funding of health care; therole of hospitals in health care; evidence and effectiveness, and rationing. Morgan's messages on these issues are lucid.

Morgan argues that Bevan's conces- sion to general practitioners in $1948 \overrightarrow{0}$ to protect their independent contrator status, along with the sacred cow clinical freedom, has never been sēंcessfully challenged. Consequenty the medical model of health care has been perpetuated and held domi-气 nance. He suggests that replacing the Hippocratic oath with a "doctor's charter" would be the key to bringing윽 practice in line with the changed structure of the NHS.

In addition, the rise in popularity of evidence-based medicine is a clearz challenge to clinical freedom, and willọ increasingly be so if protocols and guidelines, accompanied by publie information on outcome measures, are to be part of the NHS in the future. These changes in practice are clearlyo unpalatable to the medical profession, but this has to be balanced with the ethical implications of poor practice, and the ethical decisions which aren currently hidden by individual clinicians' decisions.

The NHS has not yet won the battleN to ensure an equitable provision of $\bar{O}$ health services; Morgan frequently draws attention to the inequity at several levels. First to be highlighted is the tension doctors face between their allegiance to the Hippocratic oath, which puts the individual patient in울 the place of prime importance, and the need to consider the health of the totalब population.

The reforms at the beginning of this decade decreased equity through fragmentation; and whilst they were sold 
as increasing choice, the choosers have proven to be the general practitioners rather than the patients. In addition Morgan argues that the pseudoelement of choice has been at the expense of patient participation.

Good reference is made to alternative sources of funding, principally through international comparisons, which provide varying levels of equity compared to funding through taxation, which he suggests reinforces social solidarity and equity. However, even with a tax-based system, the NHS faces great inequity through the local rather than national approach to priority setting and rationing. The questions of how to ration and who should ration health care are explored.

Also discussed is the government's role in shaping health services. Frequent reference to the past is balanced by a consideration of how, in the future, Labour's role will play out, given the indications thus far about how the government is approaching the health issues of the country.

The references to international approaches to health care provide useful comparisons, where they are present; it is disappointing though that this opportunity to inform the "Great British Health Debate" neglects to make greater reference to international models. Europe is an element of the equation which has also been skirted, even though it would have brought an interesting dimension to the dreams of the future.

The author acknowledges that issues relating to mental illness and care in the community have not been covered; in addition there is very little discussion, either past or future, of the role of public health, nurses or professions allied to medicine. It is also surprising that the significant power and influence of the royal colleges has not been given greater consideration. Despite the focus on the acute sector, the book is still informative and provocative in its consideration of how health care may be provided in the future given that no change is not an option. Morgan has achieved his aim to be of interest to both the public and health professionals, although I doubt whether he has realised his aim to be readable to readers of any newspaper.

\section{People-centred Health Promotion}

John Raeburn and Irving Rootman,
Chichester, John Wiley, 1998, 228
pages, $£ 34.95$ (hb), £19.99 (pb).

This book seeks to place people's experience of health and its determinants at the core of conceptualisation and practice in health promotion. Attempting to avoid the extremes of a "lifestyle" approach which emphasises individual responsibility for healthrelated behaviour and a "social model" which focuses on social and environmental factors influencing health status, the authors argue for an approach which recognises the rights of individuals, within their respective communities, to make decisions regarding their health and wellbeing. In such terms, the role of health promotion is to facilitate the actions and decisions of citizens rather than to seek to determine them.

The book is targeted at students and health professionals, but its tone is not that of a formal textbook. Rather than attempting a balanced review of the field, it seeks to stimulate debate regarding the basis and scope of health promotion. It does this by presenting, and then elaborating upon, a clear thesis. The principles which should govern health promotion are: peoplecentredness (a focus on the "everyday experience of people, from the perspective of their natural community settings"), empowerment, an orientation towards community development, participation (across all sectors of a community), an emphasis on quality of life (rather than disease or disease prevention) and a commitment to evaluation.

This thesis is first presented in the context of a useful historical review of the development of the discipline of health promotion. The authors subsequently seek to locate their proposals within current political and academic debates regarding such areas as individualism and collectivism, and positivism and post-modernism. This analysis is rather brief, and tends to position the proposed approach through compromise between standpoints, rather than by rigorous analysis of the issues at hand. This may suit the pragmatist and, indeed, the overall goal of the volume, but will frustrate the reader interested in careful appraisal of the epistemological and ethical bases of health promotion.
Subsequent chapters then consider the characteristics of a "peoplecentred" approach to health promotion in more detail. Consideration is given to the value of a broad "qualityof-life" perspective, empowerment, community development, and finally cultural and spiritual issues. This material very much elaborates upon the value base for health promotion being proposed by the authors: the need to extend consideration beyond health to such concepts as wellbeing and belonging; the valuing of the experience and judgment of individuals and communities, and the role of professionals in "strength-building", rather than persuading or educating, within local communities. The style, in asserting such principles rather than evaluating them with respect to others, builds a coherent thesis, but does not readily encourage debate. A less polemical approach - alerting the reader to more points of ambiguity and contestabilty - might have served the authors' stated goal more in this respect.

The final section of the book explores the application of the proposed model in health-promotion practice. This includes a description of a model for implementing programmes - the People System - and also a range of case studies planned, or analysed, with respect to the model. These are useful for clearly showing how some of the principles considered by the authors earlier in the text could be put into operation.

The final chapter begins with this statement from the authors: ". .. we want to indulge ourselves by providing our vision of what an ideal society might be like based on PCHP [peoplecentred health promotion] principles." Deconstruction of this sentence reveals the core function - and indeed core strengths and weaknesses - of this text. The book clearly articulates a nativist, relativistic position on the promotion of health and, indeed, more broadly on the development of humane society. For readers sympathetic to this view, the book provides a myriad of quotations and examples to support their position. For readers sceptical of assumptions underpinning such a vision, however, there is little in the way of crafted, reasoned debate within the current volume to persuade them. In consequence, despite its interest as a source-book within the field, the book is unlikely to contribute significantly to required debate regarding such important issues as the respective roles of the individual and 